\title{
UV-B absorbing and bioactive secondary compounds in lichens Xanthoria elegans and Xanthoria parietina: A review
}

\author{
Vilmantas Pedišius
}

Instrumental Analysis Open Access Centre, Faculty of Natural Sciences, Vytautas Magnus university, Vileikos g. 8-212, LT-44404, Kaunas, Lithuania

\begin{abstract}
Secondary metabolites are the bioactive compounds of plants which are synthesized during primary metabolism, have no role in the development process but are needed for defense and other special purposes. These secondary metabolites, such as flavonoids, terpenes, alkaloids, anthraquinones and carotenoids, are found in Xanthoria genus lichens. These lichens are known as lichenized fungi in the family Teloschistaceae, which grows on rock and produce bioactive compounds. A lot of secondary compounds in plants are induced by UV (100-400 nm) spectra. The present review showcases the present identified bioactive compounds in Xanthoria elegans and Xanthoria parietina lichens, which are stimulated by different amounts of UV-B light $(280-320 \mathrm{~nm})$, as well as the biochemistry of the UV-B absorbing compounds.
\end{abstract}

Key words: UV-B, Xanthoria parietina, Xanthoria elegans, parietin, phenolic compounds, carotenoids, anthraquinone

DOI: $10.5817 / \mathrm{CPR} 2020-2-19$

\section{Introduction}

UV-B light plays an important role in nature, yet it may cause adverse effects in high amounts of it. Chlorofluorocarbons are mainly responsible for the depletion of ozone layer which results in an increase of UV-B (280 to $320 \mathrm{~nm}$ ) irradiation of earth's environment and cause adverse effects on flora and crops (Yavaş et al. 2020). Though according to NASA, the ozone hole is on its way to recovery, it will still be a considerable time before UV-B levels reach pre-industrial limits (Takshak and Agrawal 2019). Moreover, UV-B radiation is harmful to plants, animals and humans, specifically to their proteins, lipids, membranes and DNA (Gu et al. 2010, Yavaş et al. 2020). For example, enhanced concentrations of the indole 1-methoxy-3indolylmethyl glucosinolate were reported to result in the formation of DNA adducts (Glatt et al. 2011). However, the synthesized plant secondary metabolites (PSMs) can provide benefits for both ends of the bio- based food chain - humans and plants alike (Schreiner et al. 2012).

Many secondary metabolites, like flavonoids, alkaloids, terpenoids, phenolics, carotenoids, glucoseinolates, anthraquinones, sterols, lignin, etc., are UV-B absorbing compounds $(\mathrm{Gu}$ et al. 2010, Takshak and

Received August 8, 2020, accepted November 19, 2020.

*Corresponding author: V. Pedišius < vilmantas.pedisius@vdu.lt> 
Agrawal 2019, Yavaş et al. 2020). The amount of UV-B radiation plants were exposed to plays a big role in synthesis of secondary metabolites. A sufficient amount of UV-B may increase the amount of secondary metabolites; however, an overexposure usually decreases their amount.
This review is focused on secondary metabolites that absorb UV-B radiation in Xanthoria elegans and Xanthoria parietina. The two species are reported to be rich in UV-B screening compounds (see e.g. Al-Amoody et al. 2000, Goga et al. 2020).

\section{Geographical distribution of Xanthoria elegans and Xanthoria parietina in Polar Regions of the Earth}

The differences between lichen species growing in Polar and in Alpine Regions can be looked at in two ways: UV irradiance and temperature. The Alpine populations receive $3-5$ times higher UV-B irradiance than their Arctic counterparts from Arctic Svalbard (Norway) because of latitudinal and altitudinal gradients in UV-B irradiance (Nybakken et al. 2004).

Temperature also has a significant effect on relative growth rate (RGR) such that of $X$. elegans. Originating from sites with lower mean annual temperatures, $X$. elegans had significantly higher RGRs at all test temperatures between 2 and $18^{\circ} \mathrm{C}$ (Murtagh et al. 2002). The parietin synthesis in these parietin-deficient sam-

\section{UV-B irradiation in vitro}

The existence of a specific UV-B photoreceptor, which detects UV-B radiation and initiates a signaling cascade, was proposed several decades ago by Wellmann (1983). However, it is only in recent years that substantial progress was made in identifying this photoreceptor and components of the downstream signaling pathway (Schreiner et al. 2012).

Many factors are involved in secondary metabolite synthesis under UV-B exposure. The intensity and time (for which the sample is exposed to UV-B radiation) plays an important role. In the study of Estêvao (2015), algal lichen $X$. elegans ples increased with decreasing latitude of their sampling location, which may imply that the synthesis of pigments is habitat specific. Arctic populations therefore maintain a high level of screening pigments in spite of low ambient UV-B, and the studied lichen species presumably may tolerate an increase in UV-B radiation due to the predicted thinning of the ozone layer over polar areas (Nybakken et al. 2004). Enhanced metabolic activity might also be an adaptation for growth in colder climates (Murtagh et al. 2002). Antarctic higher plants and autotrophic organisms have a high capacity to synthetize photoprotective secondary compounds when exposed to increased levels of UV-B (Estêvao 2015).

samples were exposed to different doses of UV-B (280-320 nm) - low $\left(0.7 \mathrm{~W} \mathrm{~m}^{-2}\right)$, medium $\left(1.5 \mathrm{~W} \mathrm{~m}^{-2}\right)$ and high $\left(3.0 \mathrm{~W} \mathrm{~m}^{-2}\right)$ for 5 days. Results showed that when exposed to a low dose of UV-B radiation or a short-term treatment, lichen species exhibited an increase in UV-B screening pigments in order to protect the lichen photobiont against UV-B damage (Estêvao 2015). Thus, photosynthetic secondary metabolites (PSMs) are increasingly recognized and made for the use of sunscreens and cosmetics (Takshak and Agrawal 2019). However, Estêvao's study has shown that a decrease of UV-B screening compounds 
occurred after exposition to a high dose of UV-B radiation or a long-term treatment. It is also important to be mindful of UV light exposure, because it is useful in optimizing total biomass and metabolite production in controlled environments. Brechner et al. (2011) preformed dose treatments with 55- day-old Hypericum perforatum grown under $400 \mu \mathrm{mol} \cdot \mathrm{m}^{-2} \cdot \mathrm{s}^{-1} \mathrm{PAR}$ for $16 \mathrm{~h}$ a day. Three UV light treatments were evaluated: a single dose, a daily dose and an increasing daily dose. A daily dose and an increasing daily dose did not produce significantly higher increase in secondary metabolites compared to the single dose treatments. (Brechner et al. 2011). In another study, basil (Ocimum basilicum) was exposed to UV-B radiation dose of $16 \mu \mathrm{mol} \cdot \mathrm{m}^{-2} \cdot \mathrm{s}^{-1}$ (equal to $18.7 \mathrm{~kJ} \cdot \mathrm{m}^{-2} \cdot \mathrm{h}^{-1}$ ). Concentrations of anthocyanin, phenolics, and flavonoids in green basil leaves in-

\section{Use of $U V-B$ radiation treatments}

Targeted low dosage UV-B radiation treatments as emerging technology may be used to generate fruit, vegetables, and herbs enriched with secondary plant metabolites for either fresh consumption or as a source for functional foods and nutraceuticals, resulting in increased ingestion of these health-promoting substances (Schreiner et al. 2012, Takshak and Agrawal 2019). The UV-B induced secondary metabolites are active components of herbal drugs (Gu et al. 2010). For example, increased concentrations of the aliphatic 4-methylsulfinylbutyl glucosinolate is associated with anti-carcinogenic properties due to this metabolite's effect on the upregulation of phase II detoxification enzymes and inhibition of cell proliferation by either inducing apoptosis or cell cycle creased under all UV-B treatments by $9 \%-18 \%, 28 \%-126 \%$, and $80 \%-169 \%$, respectively, where $1 \mathrm{~h} \cdot \mathrm{day}^{-1}$ for 2 days UV-B radiation was the optimal condition (Dou et al. 2019). Strong positive correlations between the concentrations of phenolic compounds under the highest UV-B dose $\left(102 \mathrm{~kJ} \cdot \mathrm{m}^{-2} \cdot\right.$ day $\left.^{-1}\right)$ in sub-chronic experiments were shown, where four different UV-B doses $\left(8.5,34,68,102 \mathrm{~kJ} \cdot \mathrm{m}^{-2}\right.$. day $^{-1}$ ) were used over 6 days (Mosadegh et al. 2018).

In natural environment of the Himalayan region, $X$. elegans was exposed to natural radiation over the time of $120 \mathrm{~h}$. The maximum average UV-B irradiance (4.38 MED/h - Minimal Erythemal Dose per hour) was recorded at $72 \mathrm{~h}$, whereas minimum was $1.72 \mathrm{MED} / \mathrm{h}$ at $120 \mathrm{~h}$. The average was $3.426 \mathrm{MED} / \mathrm{h}$.

arrest (Glatt et al. 2011).

One of the dominant compounds in the Xanthoria genus is parietin. Parietin, extracted from $X$. parietina while dissolved in ethanol, strongly absorbs UV-B radiation (absorption peak at $288 \mathrm{~nm}$ ), followed by a minimum absorption in the UV-A range, and a second peak at blue wavelengths (431 nm) (Gauslaa and Ustvedt 2003). Field experiments with extracted (parietin deficient) $X$. elegans thalli cultivated under various filters showed that UV-B was essential for the induction of parietin synthesis - only $12 \%$ of the original content of parietin was resynthesized with the PAR (photosynthetically active radiation) treatment, whereas as much as $35 \%$ was resynthesized with the PAR + UV treatment (Nybakken et al. 2004). 


\section{Biochemistry of $U V$-induction of $U V-B$ absorbing compounds}

The synthesis of compounds that are UV-B absorbing (flavonoids, flavanol glucosides and hydrocycinnamates) share the phenylpropanoid biosynthesis pathway. The pathway has the amino acid phenylalanine as the substrate. The enzyme phenylalanine ammonia lyase (PAL) catalyses the formation of the cinnamic acid by non-oxidative deamination of the amino acid. Then, the hydroxylation of the cinnamic acid is catalyzed by cinnamate 4-hydroxylase $(\mathrm{C} 4 \mathrm{H})$ to $\mathrm{p}$-coumaric acid which then is ligated with coenzyme $\mathrm{A}$ by 4-coumarate: CoA ligase (4CL) to provide the first precursor of the flavonoid biosynthetic pathway. For entry into the flavonoid biosynthetic pathway, 4-coumarateCoA is conjugated with 3 molecules of malonyl-CoA by chalcone isomerase (CHI; TT5, and then flavanone 3-hydroxylase (F3H; TT6) turns naringenin into dihydrokaempferol. Flavanol synthase (FLS) converts dihydrokaempferol into kaempferol, the enzyme flavonoid 3'-hydroxylase (F3'H; TT7) hydroxylates its B ring in the 3 ' position to have dihydroquercetin. In the end, FLS changes dihydroquercetin to quercetin. Glycocylation is then carried out by different sugar-specific flavanol O-glycosyl transferases to form kaemferol 3- or 7-Orhamnosyls or quercetin 3O-glucosyls (Jordan 2017).

Often when there is a question of how does UV-B induction of secondary metabolites works, the role of glucosinolates (GS) comes up (Mewis et al. 2012, Schreiner et al. 2012, $\mathrm{Zu}$ et al. 2010). Glucosinolates are sulfur-rich secondary metabolites characteristic to the Brassicales order with important biological and economic roles in plant defense. They are sulfonated thioglycosides sharing a common glycone moiety with a variable aglycone side chain. Based on the side chain structure, GS are divided into three classes: aliphatic GS derived principally from methionine, indolyl
GS from tryptophan, and aromatic GS from phenylalanine ( $\mathrm{Zu}$ et al. 2010). Aliphatic 4-methylsulfinylbutyl glucosinolate is associated with anticarcinogenic properties due to this metabolite's effect on the upregulation of phase II detoxification enzymes and inhibition of cell proliferation by either inducing apoptosis or cell cycle alteration. GS biosynthesis proceeds through three independent steps: (i) chain elongation of selected precursor amino acids; (ii) formation of the core GS structure; and (iii) side chain modifications (Mewis et al. 2012). It was shown that interspecific induction of GS in broccoli sprouts was affected by UV-B pre-treatment (Schreiner et al. 2012). UV-B-mediated induction of glucosinolates (GS), especially of 4-methylsulfinylbutyl GS and 4-methoxy-indol-3-ylmethyl GS, while carotenoids and Chl levels remained unaffected (Mewis et al. 2012).

There are other biochemical factors that may contribute to the UV-B induction of secondary metabolites, which are not directly correlated to these compounds' synthesis. Several antioxidants, such as e.g. SOD, POD, APX and CAT activities had been associated with UV-B exposure, as these enzymes acted as antioxidant compounds to help reduce photooxidative damage in plant leaves. When the accumulation of active oxygen exceeded the scavenging activity of antioxidant systems, active oxygen accumulation could lead to the depression of antioxidant enzyme activity and an increase in the degree of membrane lipid peroxidation ( $\mathrm{Zu}$ et al. 2010). UV-B effect of inhibition of the down-regulation of chloroplast diatoxanthin epoxidation was seen as well in the diatom Phaeodactylum tricornutum (Mewes and Richter 2002). This process is normally controlled by the high $\Delta \mathrm{pH}$. There is an increase of diatoxanthin epoxidation, which results in the plants membrane permeabilisation. 


\section{Plant use of UV-B induced secondary metabolites}

UV-B radiation activates the self-protective secondary metabolism defense system from harmful UV-B radiation, which protects the genetic material of plants $(\mathrm{Gu}$ et al. 2010, Schreiner et al. 2012). UV-B

\section{Phenolic compounds}

Phenolic compounds are commonly known as plant secondary metabolites that hold an aromatic ring bearing at least one hydroxyl groups. There are many types of phenolic compounds, such as isoflavonoids, flavonols, flavones, anthocyanins, anthraquinones and phenolic acids. Total soluble phenols were extracted with $80 \%$ methanol and measured using Folin-Ciocalteu (gallic acid as standard, $750 \mathrm{~nm}$ ). Phenolic acids contributed to the observed increase in total soluble phenols. Further on, using LC system, it was shown, that among lichen specific metabolites, vulpinic acid and ergosterol increased while usnic acid and atranorin decreased after UV exposure. The accumulation of parientin was not affected (Kováčik et al. 2011). Atranorin is produced by esterification of two different precursors, methyl $\beta$-orcinol carboxylate and haematommic acid. Atranorin and usnic acid possess antifungal activity, are strong inhibitors of ornithine decarboxylase and arginine de-

\section{Flavanoids}

Flavonoids (or bioflavonoids) are a class of polyphenolic plant and fungus secondary metabolites. Flavonoids have the general structure of a 15-carbon skeleton, which consists of two phenyl rings (A and $\mathrm{B}$ ) and a heterocyclic ring (C). There are not a lot of papers exemplifying flavonoid content in $X$. elegans. However, in the study done by Kováčik et al. (2011), total soluble flavonoids were extracted with $80 \%$ methanol and measured using induced secondary metabolites also alter reproductive ability, early ripening, and trophic interactions, such as plant herbivore, fungi and bacteria resistance (Schreiner et al. 2012, Yavaş et al. 2020).

carboxylase that affect the polyamine metabolism. Atranorin alone was also reported for trypsin inhibition and moderate antioxidant activity (Zambare and Christopher 2012). Usnic acid has been used for pharmaceutical and cosmetic product development. For example, usnic acid was used in anticeptic products in Germany (Camillen 60 Fudes spray and nail oil) and Italy (Gessato shaving) (Elkhateeb and Daba 2019). Strong antimicrobial, antitumor and anti- insecticidal activity is present in usnic acid. It inhibits the growth of the Gram-positive bacteria Staphylococcus aureus, Bacillus subtilis and Bacillus megaterium, but has no effect on the Gramnegative bacteria. It shows inhibitory effects on the cell growth and proliferation of two different human cancer cell lines the breast cancer cell line T-47D and the pancreatic cancer cell line Capan-2. Bioassay of Culex pipiens larvae revealed that the LC50 value was 0.9 ppm (Zambare and Christopher 2012).

$\mathrm{AlCl}_{3}$ method (using quercetin as standard, $420 \mathrm{~nm}$ measurement with spectrophotometer), which is a common method to identify total flavonoids. Composition of flavonoids in $X$. parietina was not significant. Flavonoids formed a small part of total soluble phenols, which could be explained by a low volume of photobiont cells in lichen's thalli (up to $10 \%$ in average) (Kováčik et al. 2011). 


\section{Anthraquinones}

Anthraquinones (also known as anthraquinonoids) are a class of naturally occurring phenolic aromatic organic compounds with formula $\mathrm{C}_{14} \mathrm{H}_{8} \mathrm{O}_{2}$. The term anthraquinone, however, refers to the isomer (9,10- anthraquinone), wherein the keto groups are located on the central ring. $X$. elegans has cortical UV-B absorbing anthraquinone pigments, mainly the orange parietin (physcion) (Nybakken et al. 2004). An isolated $X$. parietina mycobiont produces parietin on culturing media containing ribitol. Ribitol, the carbohydrate delivered from the photobiont, increases the parietin resynthesis substantially (Solhaug and Gauslaa 2004). However, whereas aposymbiotically cultured $X$. parietina mycobiont needs ribitol for anthraquinone production, aposymbiotically cultured mycobionts of other Xanthoria species might produce anthraquinones on a wider range of carbon sources. For example, a type II polyketide synthase (PKSs) is also responsible for anthraquinone biosynthe-

\section{Alkaloids}

Alkaloids are biologically active heterocyclic chemical compounds containing nitrogen. They are categorized as true alkaloids, protoalkaloids and pseudoalkaloids, and have pharmacological properties and

\section{Terpenes}

Terpenes (or terpenoids) are 5-carbon compounds give rise to terpene precursors such as geranyl, farnesyl, squalene, phytoene, etc. via condensation reactions in- sis. Among polyketide- type lichen substances, polyketide synthase is a secondary metabolite recently considered an important factor to understanding the architecture of PKS enzymes (Stocker-Wörgötter et al. 2013). Another anthraquinone, structurally similar to parietin and present in $X$. elegans, is emodin (Brunauer et al. 2007). The analyses of samples from general northern area of two species of the genus Xanthoria ( $X$. candelaria and $X$. parietina) revealed the almost continual presence of emodin, at quantitative domination (10 $000 \mathrm{ng} / \mathrm{g}$ and more), as well as traces of alternariol (Burkin and Kononenko 2015). Other anthraquinones, like 1-O-methylemodin, 1-O-methylphyscionbisanthrone, teloschistin monoacetate, or physcion-bisanthrone derivatives are probable precursor steps in the production of the end-product anthraquinone parietin in $X$. elegans species mycobiont (Brunauer et al. 2007, Stocker-Wörgötter et al. 2013).

significant ecological functions (Takshak and Agrawal 2019). Composition of alkaloids in Xanthoria genus is not well known and their presence has not been showcased in scientific papers yet.

volving prenyltransferases. Composition of terpenes in Xanthoria genus is not well known and their presence has not been showcased in scientific papers yet. 


\section{Caratenoids}

Carotenoids, also called tetraterpenoids, are yellow, orange, and red organic pigments that are produced by plants and algae, as well as by several bacteria and fungi. The structure of carotenoids imparts biological abilities, including photosynthesis, photoprotection, plant coloration, and cell signaling. The general structure of the carotenoid is a polyene chain consisting of

\section{Conclusion}

The present review brings the summary information about UV-B absorbing bioactive compounds in lichens $X$. elegans and $X$. parietina. The review focuses on their use in industry, protective qualities, pretreatment and identification techniques. It is reported that the main bioactive com-
9-11 double bonds and possibly terminating in rings. Mutatoxanthin was found to be the dominant carotenoid in lichen; its content varied up to $42.2 \%$ (X. elegans) of total carotenoids. Total carotenoid content of the lichen thalli investigated varied from $16.3 \mathrm{mg} / \mathrm{g}$ (X. elegans) to $94.7 \mathrm{mg} / \mathrm{g}$ dry weight (X. parietina) (Dembitsky 1992).

ponents are anthraquinones, such as parietin, emodin, physcion-bisanthrone, carotenoid muthatoxanin, and traces of flavonoids. Most of the anthraquinones were mainly identified in $X$. elegans lichen. Phenolic substances other than antraquinones were mostly identified in $X$. parietina. 
V. PEDIŠIUS

\begin{tabular}{|c|c|c|c|c|}
\hline Compound & $\begin{array}{l}\text { Secondary } \\
\text { metabolite }\end{array}$ & $\begin{array}{l}\text { Presence in } \\
\text { lichens }\end{array}$ & Chemical structure & Reference \\
\hline Parientin & anthraquinone & $\begin{array}{l}X . \text { elegans, } \\
X . \text { parientina }\end{array}$ & & $\begin{array}{l}\text { Nybakken et } \\
\text { al. (2004), } \\
\text { Solhaug and } \\
\text { Gauslaa (2004) }\end{array}$ \\
\hline Emodin & anthraquinone & X. elegans & & $\begin{array}{l}\text { Brunauer et al. } \\
(2007)\end{array}$ \\
\hline $\begin{array}{l}\text { Physcion- } \\
\text { bisanthrone }\end{array}$ & anthraquinone & X. elegans & $\begin{array}{c}\text { (structure presented is } \\
\text { of bisanthrone) }\end{array}$ & $\begin{array}{l}\text { Brunauer et al. } \\
(2007)\end{array}$ \\
\hline Telochistin & anthraquinone & X. elegans & & $\begin{array}{l}\text { Brunauer et al. } \\
(2007), \\
\text { Zambare and } \\
\text { Christopher } \\
(2012)\end{array}$ \\
\hline $\begin{array}{l}\text { 1-O- } \\
\text { methylemodin }\end{array}$ & anthraquinone & X. elegans & & $\begin{array}{l}\text { Stocker- } \\
\text { Wörgötter et } \\
\text { al. (2013) }\end{array}$ \\
\hline Brassicasterol & sterol & $X$. parientina & & Cleary (2019) \\
\hline
\end{tabular}




\begin{tabular}{|c|c|c|c|c|}
\hline $\begin{array}{l}\text { Bioactive } \\
\text { compound }\end{array}$ & $\begin{array}{l}\text { Secondary } \\
\text { metabolite } \\
\text { type }\end{array}$ & $\begin{array}{l}\text { Presence in } \\
\text { lichens }\end{array}$ & Chemical structure & Reference \\
\hline Lichesterol & sterol & $X$. parientina & & $\begin{array}{l}\text { Cleary } \\
(2019)\end{array}$ \\
\hline Mutatoxanthin & caratenoid & $X$. parientina & & $\begin{array}{l}\text { Dembitsky } \\
\text { (1992) }\end{array}$ \\
\hline Atranorin & $\begin{array}{l}\text { phenolic } \\
\text { compound }\end{array}$ & $X$. parientina & & $\begin{array}{l}\text { Dias and } \\
\text { Urban } \\
(2009)\end{array}$ \\
\hline Sekikaic acid & $\begin{array}{l}\text { phenolic } \\
\text { compound }\end{array}$ & $X$. parientina & & $\begin{array}{l}\text { Dias and } \\
\text { Urban } \\
(2009)\end{array}$ \\
\hline$(+)$-usnic acid & $\begin{array}{l}\text { phenolic } \\
\text { compound }\end{array}$ & X. parientina & & $\begin{array}{l}\text { Dias and } \\
\text { Urban } \\
(2009)\end{array}$ \\
\hline Vulpinic acid & $\begin{array}{l}\text { phenolic } \\
\text { compound }\end{array}$ & $X$. parientina & & $\begin{array}{l}\text { Kováčik } \\
\text { et al. } \\
(2011)\end{array}$ \\
\hline
\end{tabular}

Table 1. UV-B absorbing secondary metabolites in $X$. parientina and X. elegans (complied fom the referenced scientific papers. The structural chemical formulas are taken from chemspider.com website [1]. 


\section{References}

Al-Amoody, A.A., Yayman, D., KaAn, T., Özkok, E.A., Özkan, A., Özen, E. and Cobanoglu ÖzYigitoglu, G. (2020): Role of lichen secondary metabolites and pigments in UV-screening phenomenon in lichens. Acta Biologica Turcica, 33: 35-48. (In Turkish).

Brechner, M. L., Albright, L. D. and Weston, L. (2011): Effects of UV-B on secondary metabolites of St. John's wort (Hypericum perforatum L.) grown in controlled environments. Photochemistry and Photobiology, 87(3): 680-684. https://doi.org/10.1111/j.1751-1097.2011. 00904.x

BrunAuER, G., Hager, A., Grube, M., TÜRK, R. and STOCKER-WÖRGÖTter, E. (2007): Alterations in secondary metabolism of aposymbiotically grown mycobionts of Xanthoria elegans and cultured resynthesis stages. Plant Physiology and Biochemistry, 45(2): 146-151. https://doi.org/ 10.1016/j.plaphy.2007.01.00 4

Burkin, A. A., Kononenko, G. P. (2015): Metabolites of toxigenic fungi in lichens of genera Nephroma, Peltigera, Umbilicaria, and Xanthoria. Biology Bulletin of the Russian Academy of Sciences, 42(6): 486-492. https://doi.org/10.1134/S1062359015060023

Cleary, M. (2019): Chapter 1_2. Journal of Chemical Information and Modeling, 53(9): 16891699. https://doi.org/10.1017/CBO9781107415324.004

Dembitsky, V. M. (1992). Lipids of lichens. Progress in Lipid Research, 31(4): 373-397. https://doi.org/10.1016/0163- 7827(92)90002-Z

Dias, D. A., Urban, S. (2009): Natural Product Communications Phytochemical Investigation of the Australian Lichens, pp. 3-8.

Dou, H., Niu, G. and Gu, M. (2019): Pre-harvest UV-B radiation and photosynthetic photon flux density interactively affect plant photosynthesis, growth, and secondary metabolites accumulation in basil (Ocimum basilicum) plants. Agronomy, 9(8). https://doi.org/10.3390/ agronomy 9080434

Elkhateeb, W. A., DabA, G. M. (2019): Lichens, an alternative drugs for modern diseases. International Journal of Research in Pharmacy and Biosciences, 6(10): 5-9.

EsTÊVAO, D. M. M. (2015): Production of UV-B screens and changes in photosynthetic efficiency in Antarctic Nostoc commune colonies and a lichen Xanthoria elegans depend on a dose and duration of UV-B stress. Czech Polar Reports, 5(1): 55-68. https://doi.org/10.5817/CPR2015$1-6$

GAuSLAA, Y., UstVedT, E. M. (2003): Is parietin a UV-B or a blue-light screening pigment in the lichen Xanthoria parietina? Photochemical and Photobiological Sciences, 2(4): 424-432. https://doi.org/10.1039/b212532c

Glatt, H., BaAsanjav-Gerber, C., Schumacher, F., Monien, B. H., Schreiner, M., Frank, H., Seidel, A. and Engst, W. (2011): 1-Methoxy-3-indolylmethyl glucosinolate; A potent genotoxicant in bacterial and mammalian cells: Mechanisms of bioactivation. ChemicoBiological Interactions, 192(1-2): 81-86. https://doi.org/10.1016/j.cbi.2010.09.009

Goga, M., EleČKO, J., MARCinČINOVÁ, M., RuČOVÁ, D., BAČKOROVÁ, M. and BAČKOR, M. (2020): Lichen Metabolites: An Overview of Some Secondary Metabolites and Their Biological Potential. In: JM. Mérillon, K. Ramawat (eds): Co-Evolution of Secondary Metabolites. Reference Series in Phytochemistry. Springer, Cham. https://doi.org/10.1007/978-3-319-96397$6 \_57$

Gu, X. -D., Sun, M. -Y., Zhang, L., Fu, H. -W., Cui, L., Chen, R. -Z., Zhang, D.-W. and Tian, J. -K. (2010): UV-B induced changes in the secondary metabolites of Morus alba L. leaves. Molecules, 15(5): 2980-2993. https://doi.org/10.3390/molecules 15052980

JORDAN, B. R. (2017): UV-B radiation and plant life: Molecular biology to ecology. 192 p., ISBN 9781780648590

Kováčik, J., Klejdus, B., Štork, F. and MalČovskÁ, S. (2011): Sensitivity of Xanthoria parietina to UV-A: Role of metabolic modulators. Journal of Photochemistry and Photobiology B: Biology, 103(3): 243-250. https://doi.org/10.1016/j.jphotobiol.2011.0 4.002 
MEwes, H., RichteR, M. (2002): Supplementary ultraviolet-B radiation induces a rapid reversal of the diadinoxanthin cycle in the strong light- exposed diatom Phaeodactylum tricornutum. Plant Physiology, 130(3): 1527-1535. https://doi.org/10.1104/pp.006775

Mewis, I., Schreiner, M., NGuyen, C. N., Krumbein, A., Ulrichs, C., Lohse, M. and Zrenner, R. (2012): UV-B irradiation changes specifically the secondary metabolite profile in broccoli sprouts: Induced signaling overlaps with defense response to biotic stressors. Plant and Cell Physiology, 53(9): 1546-1560. https://doi.org/10.1093/pcp/pcs096

Mosadegh, H., Trivellini, A., Ferrante, A., Lucchesini, M., Vernieri, P. and Mensuali, A. (2018): Applications of UV-B lighting to enhance phenolic accumulation of sweet basil. Scientia Horticulturae, 229(November 2017): 107-116. https://doi.org/10.1016/j.scienta.2017. 10.043

Murtagh, G. J., Dyer, P. S., Furneaux, P. A. and Crittenden, P. D. (2002): Molecular and physiological diversity in the bipolar lichen-forming fungus Xanthoria elegans. Mycological Research, 106(11): 1277-1286. https://doi.org/10.1017/S095375620200661 5

Nybakken, L., Solhaug, K. A., Bilger, W. and GauslaA, Y. (2004): The lichens Xanthoria elegans and Cetraria islandica maintain a high protection against UV-B radiation in Arctic habitats. Oecologia, 140(2): 211-216. https://doi.org/10.1007/s00442-004-1583-6

Schreiner, M., Mewis, I., Huyskens-Keil, S., Jansen, M. A. K., Zrenner, R., Winkler, J. B., O’Brien, N. and Krumbein, A. (2012): UV-B-Induced Secondary Plant Metabolites - Potential Benefits for Plant and Human Health. Critical Reviews in Plant Sciences, 31(3): 229-240. https://doi.org/10.1080/07352689.2012.664979

Solhaug, K. A., GauslaA, Y. (2004): Photosynthates stimulate the UV-B induced fungal anthraquinone synthesis in the foliose lichen Xanthoria parietina. Plant, Cell and Environment, 27(2), 167-176. https://doi.org/10.1111/j.1365-3040.2003.01129.x

Stocker-Wörgötter, E., Cordeiro, L. M. C. and IAcomini, M. (2013): Accumulation of potential pharmaceutically relevant lichen metabolites in lichens and cultured lichen symbionts. Studies in Natural Products Chemistry (Vol. 39). https://doi.org/10.1016/B978-0444-62615-8.00010-2

TAKshaK, S., Agrawal, S. B. (2019): Defense potential of secondary metabolites in medicinal plants under UV-B stress. Journal of Photochemistry and Photobiology B: Biology, 193: 51-88. https://doi.org/10.1016/j.jphotobiol.2019.0 2.002

Wellmann, E. (1983): UV radiation in photomorphogenesis. In: W. Shropshire, H. Mohr (eds): Photomorphogenesis. Encyclopedia of Plant Physiology (New Series), vol 16. Springer, Berlin, Heidelberg. https://doi.org/10.1007/978-3-642-68918-5_29

Yavaș, İ., Ünay, A., Ali, S. and ABBAS, Z. (2020): Turkish Journal of Agriculture-Food Science and Technology UV-B Radiations and Secondary Metabolites. Turkish Journal of AgricultureFood Science and Technology, 8(1): 147-157.https://doi.org/10.24925/turjaf.v8i1.147-157.2878

Zambare, V. P., Christopher, L. P. (2012): Biopharmaceutical potential of lichens. Pharmaceutical Biology, 50(6): 778-798. https://doi.org/10.3109/13880209.2011.633 089

Zu, Y. Gang, PanG, H. H., Yu, J. H., Li, D. W., Wei, X. X., GaO, Y. X. and Tong, L. (2010): Responses in the morphology, physiology and biochemistry of Taxus chinensis var. mairei grown under supplementary UV-B radiation. Journal of Photochemistry and Photobiology B: Biology, 98(2): 152-158. https://doi.org/10.1016/j.jphotobiol.2009.1 2.001

\section{Web sources / Other sources}

[1] chemspider.com website 